\title{
Performance evaluation method of solar-assisted heat pump water heater
}

\author{
B.J. Huang *, C.P. Lee \\ Department of Mechanical Engineering, National Taiwan University, Taipei 106, Taiwan \\ Received 18 April 2006; accepted 1 June 2006 \\ Available online 4 August 2006
}

\begin{abstract}
The present study derives a simple linear correlation for the performance evaluation of different solar-assisted heat pump water heater (ISAHP). The correlation was derived from the principle of energy conservation with some simplifications. The correlation is then verified using the long-term outdoor field test data of four different ISAHP. The problems of seasonal repeatability and method of data scattering were examined. From that, a standard performance test method is proposed. The test method suggests that only the measurement of instantaneous solar incident radiation on horizontal surface, ambient temperature, hot water temperature in the storage tank, total mass of water in the storage tank and total power input to the ISAHP are required. It is suggested to select the value of COP at $T_{\mathrm{f}}-T_{\mathrm{a} \text { ave }}=15^{\circ} \mathrm{C}$ as the characteristic COP for performance comparison of ISAHP. It is found from the test results that the same performance correlation holds for ISAHP operating with single or dual energy source.
\end{abstract}

(c) 2006 Elsevier Ltd. All rights reserved.

Keywords: Heat pump; Solar-assisted heat pump; Solar energy

\section{Introduction}

National Taiwan University has been devoted to the development of integral-type solar assisted heat pump water heater (ISAHP) since 1999. Several types of ISAHP with different structures were designed and tested. Some of them are commercialized as a domestic hot water heater (Fig. 1).

The ISAHP consists of a Rankine refrigeration cycle coupled with a solar collector that acts as an evaporator. The refrigerant is expanded inside the evaporator to absorb the ambient or solar energy. By a proper design of the Rankine refrigeration cycle (heat pump) and the collector for a specific operating condition, heat may be absorbed from, rather than rejected to, the ambient. That is, ISAHP can absorb heat from solar radiation and ambient air simultaneously. ISAHP integrates the heat pump, solar collector and water storage tank together to come up with a single

\footnotetext{
* Corresponding author. Tel.: +886 223634 790; fax: +886 223640549 .

E-mail address: bjhuang@seed.net.tw (B.J. Huang).
}

unit that is easy to install. Huang and Chyng [1] first proposed the design of an integral-type solar-assisted heat pump water heater. Huang and Chyng [2] further studied experimentally the instantaneous performance characteristics of an ISAHP. Chyng et al. [3] also developed a method of analysis for ISAHP. From the long-term test result, Huang and Lee [4] found that the thermal performance of an ISAHP varies with weather conditions.

ISAHP is now accepted in commercial market as a domestic water heater. How to evaluate the performance of different ISAHP using a commonly-trusted method becomes a problem to be resolved. The development of a test standard for ISAHP is thus very important.

Ito et al. [7] showed that the evaporator temperature and the condenser temperature both influenced the COP and the compressor power, and he derived the correlation between them. Hawlader et al. [8] found the COP of a solar assisted heat pump decreased when the water temperature increased, and efficiency of the solar collector evaporator also decreased. Morrison et al. [9] also indicated that the instant COP of the air-source heat pump could be 


\section{Nomenclature}

$a, b, c, g$ constants defined in Eqs. (2) and (3)

$A, B$ constants defined in Eq. (12)

$A_{\text {eff }} \quad$ effective evaporator or surface area $\left(\mathrm{m}^{2}\right)$

$C_{p} \quad$ specific heat of water $\left(\mathrm{kJ} / \mathrm{kg}{ }^{\circ} \mathrm{C}\right)$

COP daily overall coefficient of ISAHP

$H_{\mathrm{t}} \quad$ daily total horizontal solar radiation $\left(\mathrm{J} / \mathrm{m}^{2}\right)$

$I_{\text {ave }} \quad$ daily average incident solar radiation $\left(\mathrm{W} / \mathrm{m}^{2}\right)$

$I_{\mathrm{s}} \quad$ instantaneous horizontal solar radiation $\left(\mathrm{W} / \mathrm{m}^{2}\right)$

$M \quad$ total water mass in ISAHP $(\mathrm{kg})$

$R_{i h} \quad$ symmetry factor of solar radiation pattern defined in Eq. (21)

$T$ temperature $\left({ }^{\circ} \mathrm{C}\right)$

$T_{\text {wf }} \quad$ final water temperature $\left({ }^{\circ} \mathrm{C}\right)$

$T_{\text {wi }} \quad$ initial water temperature $\left({ }^{\circ} \mathrm{C}\right)$

$T_{\mathrm{f}} \quad$ daily mean water temperature $\left({ }^{\circ} \mathrm{C}\right)=\left(T_{\mathrm{wi}}+\right.$ $\left.T_{\mathrm{wf}}\right) / 2$ $t \quad$ time (s)

$t_{\mathrm{i}} \quad$ starting time of ISAHP operation (s)

$t_{\mathrm{f}} \quad$ stop time of ISAHP operation (s)

$U_{\mathrm{a}} \quad$ overall heat transfer coefficient from the evaporator to ambient air $\left(\mathrm{W} /{ }^{\circ} \mathrm{C}\right)$

$U_{\mathrm{e}} \quad$ time average of $U_{\mathrm{a}}\left(\mathrm{W} /{ }^{\circ} \mathrm{C}\right)$

$W_{\text {comp }}$ daily total energy consumption of ISAHP (J)

$w_{\text {comp }}$ instantaneous energy consumption of ISAHP (W)

$\alpha \quad$ solar absorption coefficient of the evaporator or body surface of ISAHP

$\alpha_{e} \quad$ effective solar absorption coefficient of the evaporator or body surface of ISAHP correlated in terms of the difference between the water temperature and the ambient temperature. Although the daily overall coefficient of performance (COP) can be a performance index for an ISAHP, many factors may cause COP to vary. Both the ambient air temperature and solar radiation will affect the performance of ISAHP. The temperature of water inside the ISAHP changes hour by hour

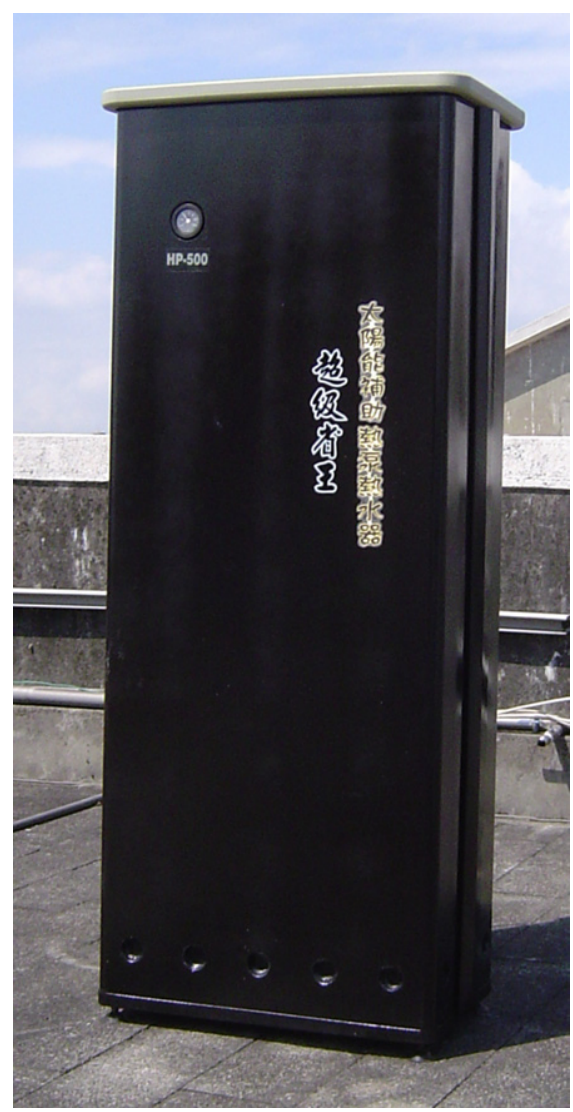

Fig. 1. Configuration of ISAHP-8. and its initial temperature (make-up city water temperature) varies season by season. Water temperature is another factor that affects the performance.

The present study intends to derive a long-term performance correlation using the outdoor test results collected from several types of ISAHP. From that, a performance test method of ISAHP may further conclude.

\section{Test samples of ISAHP}

Four samples of ISAHP with different designs were selected for the present study. All ISAHP used R134a refrigerant. Table 1 shows the design feature. There are three types of designs: type A, B and D. The main difference is the mechanism of solar energy and ambient heat absorption in the evaporator. Type A (ISAHP-2, ISAHP7) uses a direct-expansion type evaporator which directly absorbs both solar and ambient heat as shown in Fig. 2 . The evaporator of type A consists of black fins to absorb incident solar radiation directly and ambient heat via free convection. The type D (ISAHP-5) is similar to type A but with a split evaporator and heat pipe enhancement design [5] as shown in Fig. 3. The evaporator of type D is set with a tilted angle $23^{\circ}$. The design of type $\mathrm{B}$ (ISAHP-8) uses a forced-convection evaporator with fan like a traditional heat exchanger and the intake air is passing through a passage beneath the body case so that it is preheated by solar radiation incident upon the body surface.

The test of ISAHP is performed on daily total basis since it represents an overall efficiency. The test starts at 9:00 AM daily and terminates when water temperature reaches $55^{\circ} \mathrm{C}$. The water was mixed using a circulation pump before water temperature measurement. Total energy consumption of the compressor was measured by a watt meter. The daily accumulated solar radiation 
Table 1

Specification of different ISAHP used in the present study

\begin{tabular}{lllll}
\hline Type & Model & Evaporator design & $\begin{array}{l}\text { Water } \\
\text { storage (l) }\end{array}$ & $\begin{array}{l}\text { Rated compressor } \\
\text { input power (W) }\end{array}$ \\
\hline A & ISAHP-2 & Direct-expansion natural convection; (Fig. 2) direct absorption of solar radiation & 115 & 150 \\
D & ISAHP-5 & Direct-expansion natural convection; (Fig. 3) split evaporator; heat-pipe enhancement & 240 & 600 \\
A & ISAHP-7 & Direct-expansion natural convection; (Fig. 2) direct absorption of solar radiation & 130 & 250 \\
B & ISAHP-8 & Forced-convection with fan; intake air preheated by solar radiation & 200 & 250 \\
\hline
\end{tabular}

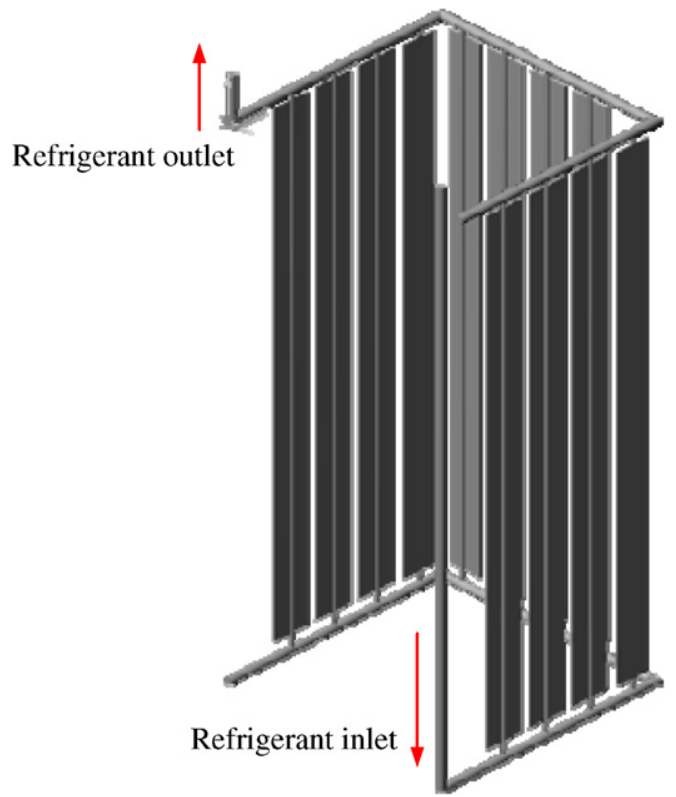

Fig. 2. Schematic diagram of type-A evaporator.

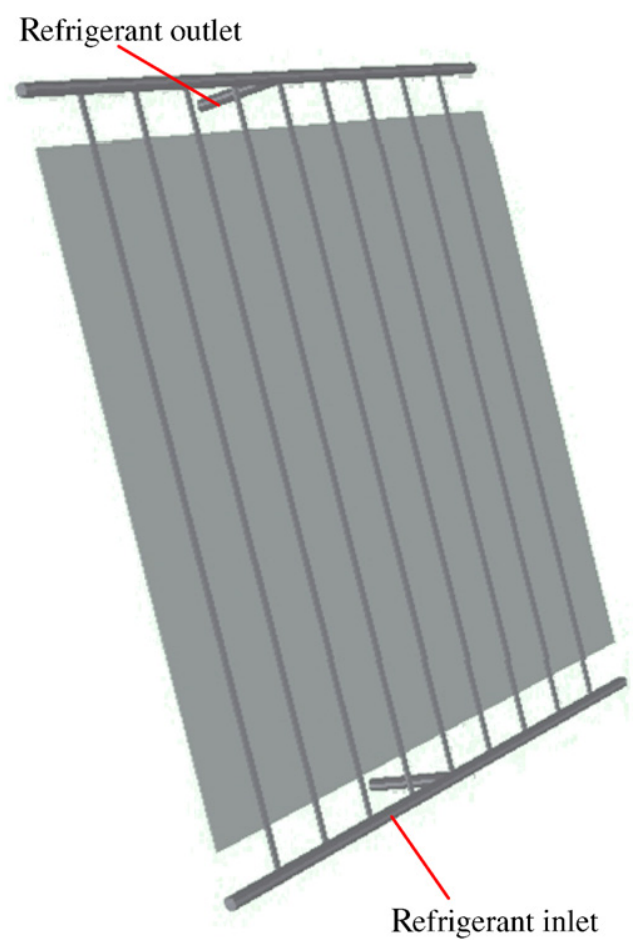

Fig. 3. Schematic diagram of type-D evaporator. incident on ISAHP in horizontal position was measured by a pyranometer. T-type thermocouples were used to measure water and ambient temperatures. Hot water is fully discharged and replaced with fresh city water at early morning before starting the ISAHP.

\section{Derivation of performance correlation of ISAHP}

\subsection{ISAHP operating at single energy source from ambient air}

The ISAHP absorbs energy from both solar radiation and ambient heat. In order to derive the performance correlation, we first try to derive a performance correlation for ISAHP operating at only one energy source (ambient heat). This corresponds to the condition of cloudy days or the performance of conventional air-source heat pump. The energy balance to ISAHP will result in the follow equation:

$M C_{p} \frac{\mathrm{d} T_{\mathrm{w}}}{\mathrm{d} t}=U_{\mathrm{a}}\left(T_{\mathrm{a}}-T_{\mathrm{e}}\right)+w_{\text {comp }}$

where $M$ is the mass of water storage $(\mathrm{kg}) ; C_{p}$ is the specific heat of water $\left(\mathrm{kJ} / \mathrm{kg}{ }^{\circ} \mathrm{C}\right) ; t$ is time (s); $U_{\mathrm{a}}$ is the overall heat transfer coefficient from the evaporator to ambient air (W/ $\left.{ }^{\circ} \mathrm{C}\right) ; T_{\mathrm{w}}$ is the water temperature in the storage tank; $T_{\mathrm{a}}$ is the ambient temperature $\left({ }^{\circ} \mathrm{C}\right) ; T_{\mathrm{e}}$ is the evaporator temperature $\left({ }^{\circ} \mathrm{C}\right) ; w_{\text {comp }}$ is the power input to the compressor $(\mathrm{W})$.

The measurement of evaporator temperature $T_{\mathrm{e}}$ usually requires installing temperature probes at various locations of the evaporator and taking an average value. This is quite complicated and sometimes difficult to obtain an accurate result. Simplification is thus necessary.

We observed from many test results of ISAHP that $T_{\mathrm{a}}-T_{\mathrm{e}}$ and $w_{\text {comp }}$ are proportional to $T_{\mathrm{w}}-T_{\mathrm{a}}$, as shown in Fig. 4 for ISAHP-2 on one particular day. This implies that the following relations may hold:

$T_{\mathrm{a}}-T_{\mathrm{e}}=a\left(T_{\mathrm{w}}-T_{\mathrm{a}}\right)+b$,

$w_{\text {comp }}=c\left(T_{\mathrm{w}}-T_{\mathrm{a}}\right)+g$.

Substituting Eqs. (2) and (3) into Eq. (1) and taking integral, we obtain

$$
\begin{aligned}
& \int_{t_{\mathrm{i}}}^{t_{\mathrm{f}}} M C_{p} \frac{\mathrm{d} T_{\mathrm{w}}}{\mathrm{d} t} \mathrm{~d} t=\int_{t_{\mathrm{i}}}^{t_{\mathrm{f}}} U_{\mathrm{a}}\left(T_{\mathrm{a}}-T_{\mathrm{e}}\right) \mathrm{d} t+\int_{t_{\mathrm{i}}}^{t_{\mathrm{f}}} w_{\text {comp }} \mathrm{d} t \\
& \frac{\int_{t_{\mathrm{i}}}^{t_{\mathrm{f}}} M C_{p} \frac{\mathrm{d} T_{\mathrm{w}}}{\mathrm{d} t} \mathrm{~d} t}{\int_{t_{\mathrm{i}}}^{t_{\mathrm{f}}} w_{\text {comp }} \mathrm{d} t}=\frac{\int_{t_{\mathrm{i}}}^{t_{\mathrm{f}}} a U_{\mathrm{a}}\left(T_{\mathrm{w}}-T_{\mathrm{a}}\right) \mathrm{d} t+\int_{t_{\mathrm{i}}}^{t_{\mathrm{f}}} b U_{\mathrm{a}} \mathrm{d} t}{\int_{t_{\mathrm{i}}}^{t_{\mathrm{f}}} c\left(T_{\mathrm{w}}-T_{\mathrm{a}}\right) \mathrm{d} t+\int_{t_{\mathrm{i}}}^{t_{\mathrm{f}}} g \mathrm{~d} t}+1 .
\end{aligned}
$$


ISAHP-2 (2002/5/15)

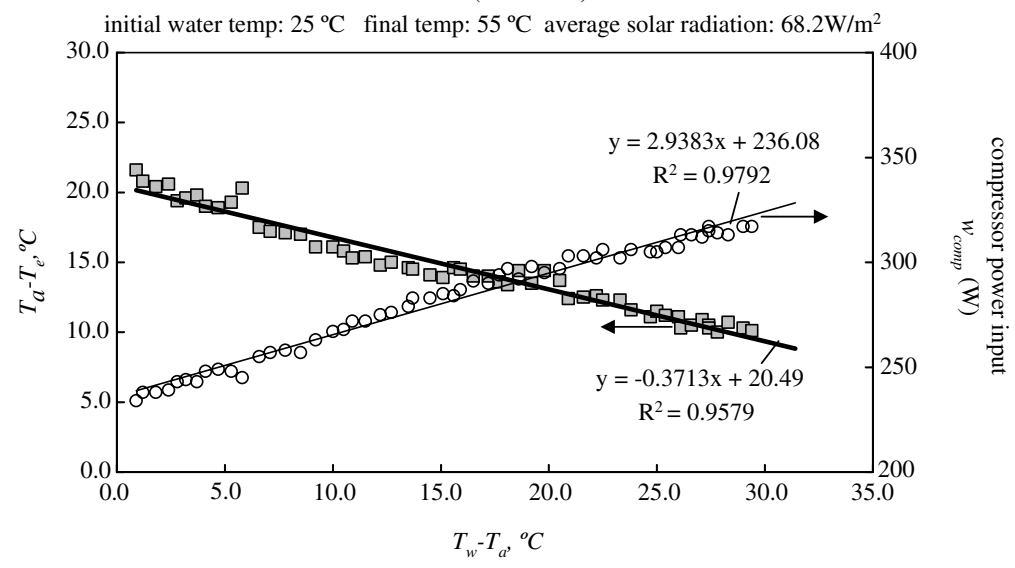

Fig. 4. ISAHP-2 outdoor test results.

Assuming constant $C_{p}$ and $U_{\mathrm{e}}$, we obtain

$$
\begin{aligned}
\mathrm{COP} \equiv & \frac{M C_{p}\left(T_{\mathrm{wf}}-T_{\mathrm{wi}}\right)}{W_{\text {comp }}} \\
& =\frac{\frac{\left(a U_{\mathrm{e}}\right)\left(\overline{T_{\mathrm{w}}}-T_{\mathrm{a}, \mathrm{ave}}\right)}{g}+\frac{b U_{\mathrm{e}}}{g}}{\frac{c\left(\overline{T_{\mathrm{w}}}-T_{\mathrm{a}, \mathrm{ave}}\right)}{g}+1}+1, \\
W_{\text {comp }} & =\int_{t_{\mathrm{i}}}^{t_{\mathrm{f}}} w_{\text {comp }} \mathrm{d} t, \\
\Delta t & =t_{\mathrm{f}}-t_{\mathrm{i}}, \\
\overline{T_{\mathrm{w}}} & =\int_{t_{\mathrm{i}}}^{t_{\mathrm{f}}} T_{\mathrm{w}} \mathrm{d} t / \Delta t, \\
T_{a, \text { ave }} & =\int_{t_{\mathrm{i}}}^{t_{\mathrm{f}}} T_{\mathrm{a}} \mathrm{d} t / \Delta t, \\
U_{\mathrm{e}} \equiv & \frac{\int_{t_{\mathrm{i}}}^{t_{\mathrm{f}}} U_{\mathrm{a}}\left(T_{\mathrm{w}}-T_{\mathrm{a}}\right) \mathrm{d} t}{\int_{t_{\mathrm{i}}}^{t_{\mathrm{f}}}\left(T_{\mathrm{w}}-T_{\mathrm{a}}\right) \mathrm{d} t}=\frac{\int_{t_{\mathrm{i}}}^{t_{\mathrm{f}}} U_{\mathrm{a}}\left(T_{\mathrm{w}}-T_{\mathrm{a}}\right) \mathrm{d} t}{\Delta t\left(\overline{T_{\mathrm{w}}}-T_{\mathrm{a}, \text { ave }}\right)},
\end{aligned}
$$

where $U_{\mathrm{e}}$ is defined as the time average of $U_{\mathrm{a}} ; T_{\mathrm{wf}}$ is the final water temperature, $T_{\mathrm{wi}}$ is the initial water temperature. It is seen from Fig. 4 that $(c / g) \times\left(\overline{T_{\mathrm{w}}}-T_{\mathrm{a}, \text { ave }}\right)$ is much less than 1. Hence, it can be ignored and Eq. (4) becomes

$$
\begin{aligned}
\mathrm{COP} & \equiv \frac{M C_{p}\left(T_{\mathrm{wf}}-T_{\mathrm{wi}}\right)}{W_{\mathrm{comp}}} \\
& =\frac{a U_{\mathrm{e}}}{g} \times\left(\bar{T}_{\mathrm{w}}-T_{\mathrm{a}, \mathrm{ave}}\right)+\left(\frac{b U_{\mathrm{e}}}{g}+1\right) .
\end{aligned}
$$

The time average water temperature $\bar{T}_{\mathrm{w}}$ in Eq. (10) is related to the initial and final temperature. $\bar{T}_{\mathrm{w}}$ can be taken as the arithmetic mean of the initial and final water temperatures for simplification, that is

$T_{\mathrm{f}}=\frac{T_{\mathrm{wi}}+T_{\mathrm{wf}}}{2} \cong \bar{T}_{\mathrm{w}}$

Eq. (10) then becomes

$\mathrm{COP}=A\left(T_{\mathrm{f}}-T_{\mathrm{a}, \text { ave }}\right)+B$ where $A$ and $B$ are constants defined as

$A=\frac{a U_{\mathrm{e}}}{g} ; \quad B=\frac{b U_{\mathrm{e}}}{g}+1$.

Eq. (12) represents an approximate correlation for ISAHP operating at cloudy days (single energy source). The condition for a cloudy day is defined as the average solar radiation intensity $I_{\text {ave }}<200 \mathrm{~W} / \mathrm{m}^{2}$. It can be seen from Figs. 5 and 4 that the test results for ISAHP-2 and ISAHP-7 obey the relation of Eq. (12) very well. This verifies that Eq. (12) is the performance correlation for ISAHP operating at cloudy days with $I_{\text {ave }}<200 \mathrm{~W} / \mathrm{m}^{2}$ (see also Fig. 6).

To investigate the possibility of correlation variation in different test seasons, we used the test data collected in different seasons and plot the correlations again. Table 2 summarizes the results of ISAHP-2 operating at cloudy days with $I_{\text {ave }}<200 \mathrm{~W} / \mathrm{m}^{2}$. It shows that the performance correlation can be repeated with small errors. Table 2 also presents the effect of the number of test data points on the performance correlation results. For the test in spring season (2003/3/1-2003/5/31) with 17 test points (days), the results is almost identical with the whole year test result $(2002 / 1 / 1-2002 / 12 / 31)$ with 50 test points. The result of Table 2 indicates that the performance test result of ISAHP

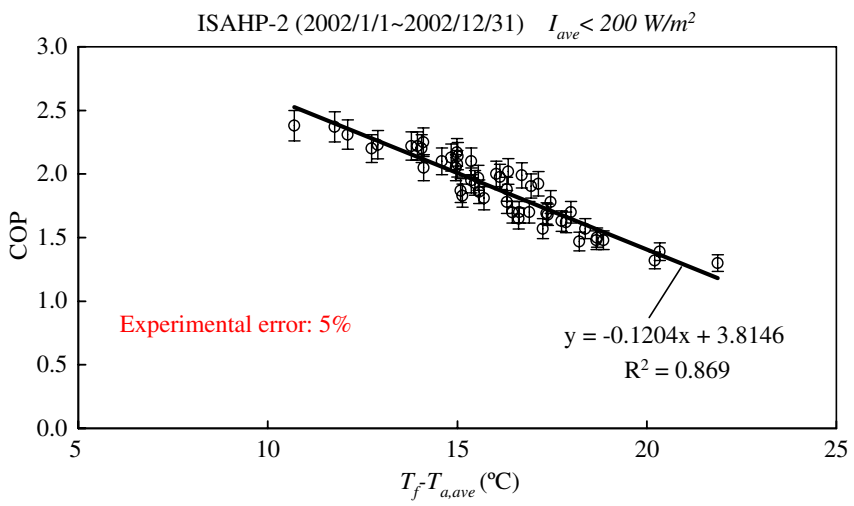

Fig. 5. Test results of ISAHP-2 at cloudy days. 


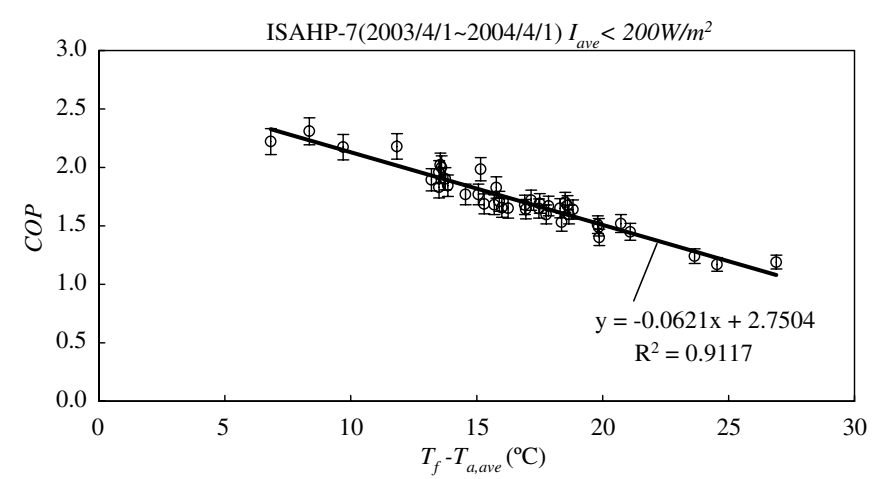

Fig. 6. Test results of ISAHP-7 at cloudy days.

Table 2

Performance test results in different seasons (ISAHP-2)

\begin{tabular}{llllll}
\hline Test period & $\begin{array}{l}T_{\mathrm{f}}-T_{\mathrm{a}, \text { ave }} \\
\text { range }\end{array}$ & $\begin{array}{l}\text { No. of } \\
\text { test } \\
\text { points }\end{array}$ & $\begin{array}{l}\text { Slope } \\
C\end{array}$ & $\begin{array}{l}\text { Intercept } \\
K\end{array}$ & $\begin{array}{l}R^{2}- \\
\text { value }\end{array}$ \\
\hline $2002 / 1 / 1-2002 / 12 / 31$ & $10-25$ & 50 & -0.120 & 3.815 & 0.869 \\
$2003 / 3 / 1-2003 / 5 / 31$ & $10-25$ & 17 & -0.117 & 3.773 & 0.935 \\
$2003 / 7 / 1-2003 / 9 / 31$ & $10-20$ & 19 & -0.103 & 3.603 & 0.785 \\
$2003 / 11 / 1-2004 / 1 / 31$ & $10-25$ & 22 & -0.115 & 3.764 & 0.855 \\
\hline
\end{tabular}

at cloudy days using the correlation, Eq. (12), is repeatable. Table 3 presents the performance test results of different ISAHP at $I_{\text {ave }}<200 \mathrm{~W} / \mathrm{m}^{2}$. The performance correlation is shown very well.

\subsection{ISAHP operating at dual energy source from solar and ambient air}

ISAHP is designed to absorb both solar and ambient energies simultaneously. For dual energy source operation, the energy balance Eq. (1) needs to be modified as

$M C_{p} \frac{\mathrm{d} T_{\mathrm{w}}}{\mathrm{d} t}=\alpha I_{\mathrm{s}} A_{\text {eff }}+U_{\mathrm{a}}\left(T_{\mathrm{a}}-T_{\mathrm{e}}\right)+w_{\text {comp }}$,

where $A_{\text {eff }}$ is the effective surface of ISAHP for absorbing solar radiation, $\alpha$ is the solar absorption coefficient of the evaporator or body surface of ISAHP. Taking integration of Eq. (14) from $t_{\mathrm{i}}$ to $t_{\mathrm{f}}$ in a day, we obtain

$M C_{p}\left(T_{\text {wf }}-T_{\text {wi }}\right)=\alpha_{\mathrm{e}} H_{\mathrm{t}} A_{\text {eff }}+U_{\mathrm{e}} \Delta t\left(T_{\mathrm{a}, \text { ave }}-T_{\mathrm{e}, \mathrm{ave}}\right)+W_{\text {comp }}$

$T_{\text {e,ave }}=\int_{t_{\mathrm{i}}}^{t_{\mathrm{f}}} T_{\mathrm{e}} \mathrm{d} t / \Delta t$

$\alpha_{\mathrm{e}} H_{\mathrm{t}} A_{\mathrm{eff}} \equiv \int_{t_{1}}^{t_{\mathrm{f}}} \alpha I_{\mathrm{s}} A_{\text {eff }} \mathrm{d} t$

where $H_{\mathrm{t}}$ is the accumulated solar radiation from $t_{\mathrm{i}}$ to $t_{\mathrm{f}}$.
It is seen that the first term $\alpha_{\mathrm{e}} H_{\mathrm{t}} A_{\text {eff }}$ in the right hand side of Eq. (15) represents the total solar radiation absorbed by ISAHP, the second term $U_{\mathrm{e}} \Delta t\left(T_{\mathrm{a}, \text { ave }}-T_{\mathrm{e} \text {,ave }}\right)$ represents the total energy absorbed from ambient air, the last term $W_{\text {comp }}$ is the total input energy of the compressor. Similar to the derivation of Eq. (12), we obtain from Eq. (15)

$$
\begin{aligned}
\mathrm{COP} & \equiv \frac{M C_{p}\left(T_{\mathrm{wf}}-T_{\mathrm{wi}}\right)}{W_{\mathrm{comp}}} \\
& =\frac{\alpha_{\mathrm{e}} H_{\mathrm{t}} A_{\mathrm{eff}}}{W_{\text {comp }}}+\frac{a U_{\mathrm{e}}}{g}\left(T_{\mathrm{f}}-T_{\mathrm{a}, \mathrm{ave}}\right)+\left(\frac{b U_{\mathrm{e}}}{g}+1\right) .
\end{aligned}
$$

The term $\alpha_{\mathrm{e}} H_{\mathrm{t}} A_{\mathrm{eff}} / W_{\text {comp }}$ is the ratio of total absorbed energy to the compressor input energy. From field experience, it can be assumed that $\alpha_{\mathrm{e}} H_{\mathrm{t}} A_{\text {eff }} / W_{\text {comp }}$ is a constant $k$. Hence, Eq. (18) is simplified as

$\mathrm{COP}=C\left(T_{\mathrm{f}}-T_{\mathrm{a}, \text { ave }}\right)+K$,

where $C=\frac{a U_{\mathrm{e}}}{g} ; \quad K=\frac{b U_{\mathrm{e}}}{g}+1+k$.

Eq. (17) provides a simple performance correlation for ISAHP operating with two energy sources. It is seen that the form of Eq. (19) is the same as Eq. (12) that is for single energy source operation. The simple linear correlation remains to be verified experimentally.

Fig. 7 shows the performance correlation of ISAHP-2 for $I_{\text {ave }}>200 \mathrm{~W} / \mathrm{m}^{2}$. The correlation is satisfactory, but with some scattering. The data scattering in Fig. 7 showing lower $R^{2}$ value in linear regression mainly results from the variation of instantaneous solar radiation during a day. This phenomenon is similar to that occurs in the performance test of solar hot water heater [6]. Chang et al. [6]

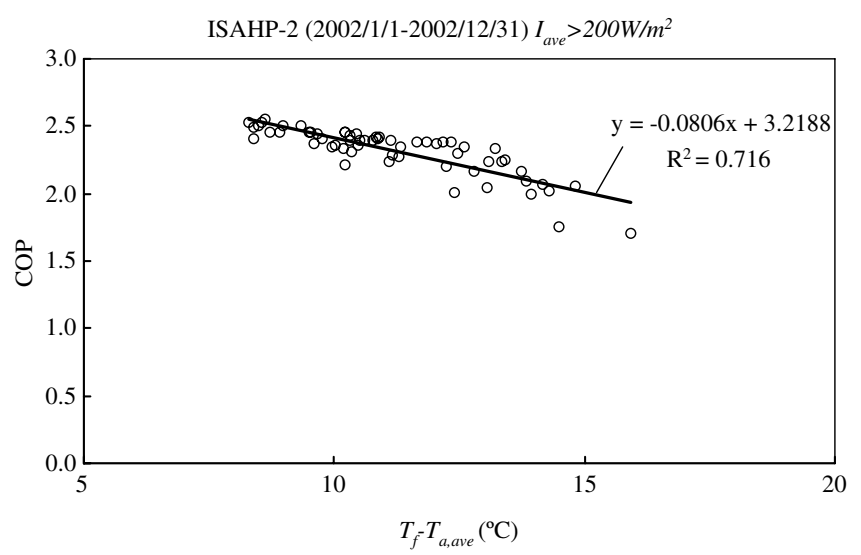

Fig. 7. Performance correlation of ISAHP-2 with $I_{\text {ave }}>200 \mathrm{~W} / \mathrm{m}^{2}$.

Table 3

Performance test results of different ISAHP at $I_{\text {ave }}<200 \mathrm{~W} / \mathrm{m}^{2}$

\begin{tabular}{llllll}
\hline Model & Test period & $T_{\mathrm{f}}-T_{\mathrm{a}, \text { ave }}$ range & No. of test points & Slope $C$ & Intercept $K$ \\
\hline ISAHP-5 & $2004 / 2 / 1-2004 / 6 / 30$ & $12-22$ & 19 & -0.099 & 3.541 \\
ISAHP-7 & $2003 / 11 / 1-2004 / 6 / 30$ & $15-27$ & 23 & -0.075 & 3.467 \\
ISAHP-8 & $2004 / 3 / 1-2004 / 4 / 30$ & $13-21$ & 17 & -0.068 & 2.871 \\
\hline
\end{tabular}




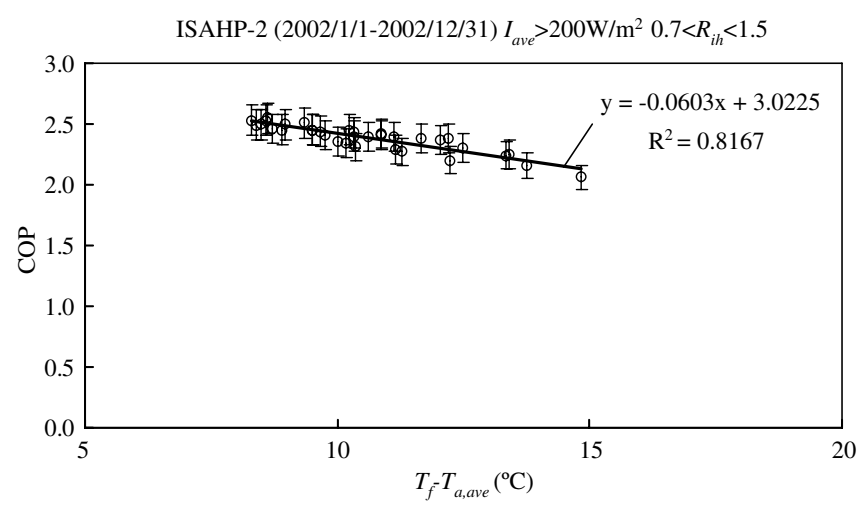

Fig. 8. Performance correlation of ISAHP-2 with $I_{\text {ave }}>200 \mathrm{~W} / \mathrm{m}^{2}$ and $0.7<R_{i h}<1.5$.

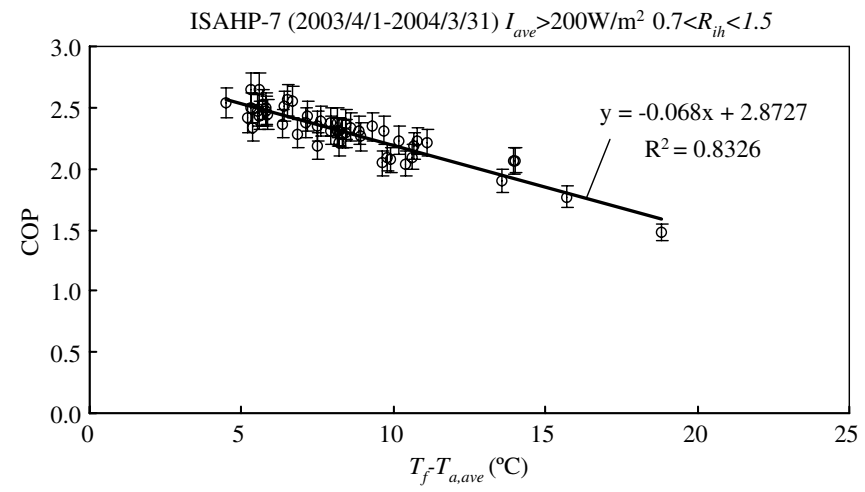

Fig. 9. Performance correlation of ISAHP-7 with $I_{\text {ave }}>200 \mathrm{~W} / \mathrm{m}^{2}$ and $0.7<R_{i h}<1.5$.

used a solar radiation symmetrical parameter $R_{i h}$ which is defined as

$R_{i h}=\frac{\int_{t_{\mathrm{i}}}^{t_{\mathrm{m}}} I_{\mathrm{s}}(t) \mathrm{d} t}{\int_{t_{\mathrm{m}}}^{t_{\mathrm{f}}} I_{\mathrm{s}} \mathrm{d} t}$,

where $t_{\mathrm{m}}$ is the time at solar noon. $R_{i h}=1$ represents the solar radiation energy is symmetrical to solar noon. $R_{i h}>1$ stands for incident solar energy is higher in the morning; $R_{i h}<1$ stands for solar energy is lower in the morning. We screened the test data to satisfy the condition $0.7<R_{i h}<1.5$ and obtain a much better linear correlation as shown in Fig. 8.

To verify the applicability of the correlation to different ISAHP, we used performance data of another ISAHP (ISAHP-7) and repeat the data processing and obtain Fig. 9 which shows good correlation again.

To investigate the possibility of correlation variation in different test seasons, we used the test data collected in different seasons and plot the correlations again. Table 4 summarizes the results of ISAHP-2. It shows that the performance correlation can be repeated with small errors. Table 4 also presents the effect of the number of test data points on the performance correlation results. For the test in summer (2003/8/1-2003/10/31) with 17 test points (days), the results is almost identical with the whole year test results (2002/1/1-2002/12/31) with 34 test points. The result of Table 4 indicates that the performance test of ISAHP using the correlation, Eq. (19), is repeatable.

Table 5 presents the performance test results of another 4 different ISAHP at $I_{\text {ave }}>200 \mathrm{~W} / \mathrm{m}^{2}$. The performance correlation is shown very well again although the ISAHP consists of 3 different types of design (type A, B, D). ISAHP-8 absorbs solar energy indirectly. That is, the intake air is first preheated by solar energy before entering the evaporator. ISAHP-5 is a heat-pipe enhanced ISAHP with split and fanless evaporator design. The performance of both ISAHP still follows the performance correlation, Eq. (19).

\section{Method of standard performance test and evaluation of ISAHP}

\subsection{Standard performance test method}

The above experimental results have shown that the performance correlation of ISAHP, Eq. (19), is adequate to correlate the thermal performance of different ISAHP.

Table 4

Performance test results in different seasons (ISAHP-2) for $I_{\text {ave }}>200 \mathrm{~W} / \mathrm{m}^{2}, 0.7<R_{i h}<1.5$

\begin{tabular}{llllll}
\hline Test period & $T_{\mathrm{f}}-T_{\mathrm{a}, \text { ave }}$ range & No. of test points & Slope $C$ & Intercept $K$ & $R^{2}$-value \\
\hline $2002 / 1 / 1-2002 / 12 / 31$ & $5-15$ & 34 & -0.0603 & 3.0225 & 0.832 \\
$2003 / 4 / 1-2003 / 6 / 30$ & $7-13$ & 16 & -0.0514 & 2.9310 & 0.787 \\
$2003 / 8 / 1-2003 / 10 / 31$ & $8-13$ & 17 & -0.0611 & 2.9936 & 0.801 \\
$2003 / 11 / 1-2004 / 1 / 31$ & $8-15$ & 15 & -0.0734 & 3.1528 & 0.944 \\
\hline
\end{tabular}

Table 5

Performance test results of different ISAHP $\left(I_{\text {ave }}>200 \mathrm{~W} / \mathrm{m}^{2}, 0.7<R_{i h}<1.5\right)$

\begin{tabular}{|c|c|c|c|c|c|c|}
\hline Model & Test period & $T_{\mathrm{f}}-T_{\mathrm{a} \text {,ave }}$ range & No. of test points & Slope $C$ & Intercept $K$ & $R^{2}$-value \\
\hline \multicolumn{7}{|c|}{ ISAHP absorbs heat from solar and ambient air $\left(I_{\text {ave }}>200 \mathrm{~W}^{2} \mathrm{~m}^{2}\right)$} \\
\hline ISAHP-2 & $2003 / 11 / 1-2004 / 1 / 31$ & $8-15$ & 15 & -0.073 & 3.153 & 0.944 \\
\hline ISAHP-5 & $2004 / 5 / 1-2004 / 7 / 31$ & $4-15$ & 17 & -0.133 & 4.233 & 0.823 \\
\hline ISAHP-7 & $2004 / 5 / 1-2004 / 7 / 31$ & $6-13$ & 15 & -0.065 & 2.935 & 0.952 \\
\hline ISAHP-8 & $2003 / 11 / 1-2004 / 6 / 30$ & $6-15$ & 11 & -0.032 & 2.939 & 0.878 \\
\hline
\end{tabular}


Thus, a method of standard test for the thermal performance of ISAHP can be developed and used for the evaluation of different ISAHP. In order to obtain a consistent and repeatable result, the following test method is suggested:

1. items of measurement: instantaneous solar incident radiation on horizontal surface $I_{\mathrm{s}}$ and ambient temperature $T_{\mathrm{a}}$, hot water temperature in the storage tank $T_{\mathrm{w}}$, total mass of water in the storage tank and total power input to the ISAHP $W_{\text {comp }}$ are required. Three minutes sampling time interval is suggested.

2. operation: the daily operation starts from $9 \mathrm{AM}$ until the water temperature reaches $55^{\circ} \mathrm{C}$. Before $9 \mathrm{AM}$, the water in the tank needs to be completely drawn off and replaced by makeup water. The initial and final water temperatures, $T_{\mathrm{wi}}$ and $T_{\mathrm{wf}}$, are measured at beginning and end of the daily operation. Every water temperature measurement requires a mixing before measurement.

3. data analysis: the daily total solar radiation $H_{\mathrm{t}}$ is calculated from instantaneous solar radiation data $I_{\mathrm{s}}$. Using the measured instantaneous data on $T_{\mathrm{wi}}, T_{\mathrm{wf}}, T_{\mathrm{a}}$, we can calculate daily $T_{\mathrm{f}}, T_{\mathrm{a} \text {,ave }}, R_{i h}, I_{\text {ave }}$ and COP according to Eqs. (8), (11), (19) and (21). Then, the results are screened for $I_{\text {ave }}>200 \mathrm{~W} / \mathrm{m}^{2}$ and $0.7<R_{i h}<1.5$. It suggests that the data covers the range $5<T_{\mathrm{f}}-T_{\mathrm{a} \text {,ave }}$ $<15^{\circ} \mathrm{C}$, with minimum number of total data points 10 for linear regression analysis using Eq. (19).

4. performance evaluation: using the two parameters $C$ and $K$ of the resultant performance correlation to evaluate the thermal performance of ISAHP.

\subsection{Method of performance evaluation}

From the performance correlation shown in Fig. 10 for $I_{\text {ave }}>200 \mathrm{~W} / \mathrm{m}^{2}$, the performance evaluation of different ISAHP can be made on a common basis. Table 6 shows the parameters of the performance correlation obtained for 4 different ISAHP. If the evaluation is based on the performance correlation curves, ISAHP-5 may be the best, ISAHP-8 is the next, ISAHP-3 is the third, and ISAHP-7 is the last. However, the slope of the performance curve of ISAHP-5 is rather high. This means that COP will decrease more quickly with increasing $T_{\mathrm{f}}-T_{\mathrm{a} \text { ave }}$. In order to simplify the performance evaluation, the COP at an adequate value of $T_{\mathrm{f}}-T_{\mathrm{a} \text {,ave }}$ can be chosen for comparison. Since $T_{\mathrm{f}}-T_{\mathrm{a} \text { ave }}=15{ }^{\circ} \mathrm{C}$ represents a reasonable operating condition for most ISAHP, we selected the value of COP at $T_{\mathrm{f}}-T_{\mathrm{a} \text { ave }}=15^{\circ} \mathrm{C}$ as the characteristic COP of a ISAHP for comparison. The results shown in Table 7 indicates that ISAHP-8 is the best at $T_{\mathrm{f}}-T_{\mathrm{a} \text {,ave }}=15^{\circ} \mathrm{C}$ among the 4 different ISAHP. This is reasonable since the evaporator of ISAHP-8 is designed with a fan to provide forced convection and the intake air is preheated by solar energy. Thus the heat transfer mechanism is better.

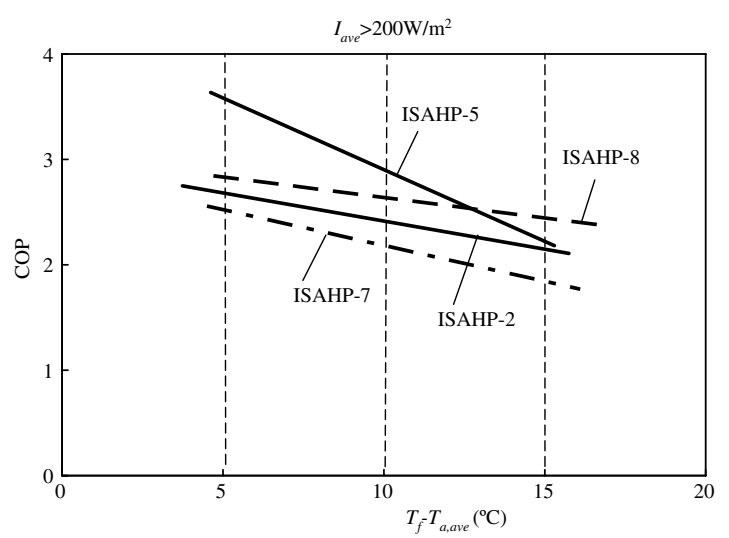

Fig. 10. Performance evaluation of different ISAHP.

Table 6

Parameters of the performance correlation for different ISAHP at $I_{\text {ave }}>200 \mathrm{~W} / \mathrm{m}^{2}$

\begin{tabular}{lcccc}
\hline Model & ISAHP-2 & ISAHP-7 & ISAHP-8 & \multicolumn{1}{c}{ ISAHP-5 } \\
\hline Intercept $K$ & 3.0225 & 2.8728 & 2.9388 & 4.2329 \\
Slope $C$ & -0.0603 & -0.0681 & -0.0316 & -0.1331 \\
\hline
\end{tabular}

Table 7

Characteristic COP value for different ISAHP at different $T_{\mathrm{f}}-T_{\mathrm{a} \text {,ave }}$

\begin{tabular}{lllll}
\hline$T_{\mathrm{f}}-T_{\mathrm{a}, \mathrm{ave}}\left({ }^{\circ} \mathrm{C}\right)$ & ISAHP-2 & ISAHP-7 & ISAHP-5 & ISAHP-8 \\
\hline 5 & 2.72 & 2.53 & 3.57 & 2.78 \\
10 & 2.42 & 2.19 & 2.90 & 2.62 \\
15 & 2.12 & 1.85 & 2.24 & 2.46 \\
\hline
\end{tabular}

\section{Discussion and conclusion}

The present study derives a simple linear correlation for the performance evaluation of different ISAHP. The correlation was derived from the principle of energy conservation with some simplifications. The correlation is then verified using the long-term outdoor field test data of 4 different ISAHP. The problems of seasonal repeatability and method of data scattering were examined. The COP of ISAHP is proportional to $T_{\mathrm{f}}-T_{\mathrm{a}, \mathrm{ave}}$ in single or dual energy source. The error of the determined COP is about $5 \%$ for the results screened for $I_{\text {ave }}>200 \mathrm{~W} / \mathrm{m}^{2}$ and $0.7<R_{i h}<1.5$. From that, a standard performance test method is concluded. It is found from the test results that the performance correlation of ISAHP has the same form for operating with single or dual energy source.

The test method suggests that only the measurement of instantaneous solar incident radiation on horizontal surface $I_{\mathrm{s}}$, ambient temperature $T_{\mathrm{a}}$, hot water temperature in the storage tank $T_{\mathrm{w}}$, total mass of water in the storage tank and total power input to the ISAHP, $W_{\text {comp }}$, are required. Thus, outdoor test using natural sunlight is feasible. It is also suggested to select the value of COP at $T_{\mathrm{f}}-T_{\mathrm{a} \text {,ave }}=$ $15^{\circ} \mathrm{C}$ as the characteristic COP of a ISAHP for 
performance comparison. This provides a simple tool for the performance evaluation of ISAHP.

\section{Acknowledgement}

The present study was supported by Energy Bureau, Ministry of Economic Affairs, Taiwan.

\section{References}

[1] B.J. Huang, J.P. Chyng, Integral type solar-assisted heat pump water heater, Renewable Energy 16 (1999) 731-734.

[2] B.J. Huang, J.P. Chyng, Performance characteristics of integral type solar-assisted heat pump, Solar Energy 71 (6) (2001) 403-414.
[3] J.P. Chyng, C.P. Lee, B.J. Huang, Performance analysis of a solarassisted heat pump water heater, Solar Energy 74 (2003) 33-44.

[4] B.J. Huang, C.P. Lee, Long-term performance of solar-assisted heat pump water heater, Renewable Energy 29 (2003) 633-639.

[5] B.J. Huang, C.P. Lee, J.P. Chyng, Heat-pipe enhanced solar-assisted heat pump water heater, Solar Energy 78 (2005) 375-381.

[6] J.M. Chang, M.C. Shen, B.J. Huang, A criterion study of solar irradiation patterns for the performance testing of thermosyphon solar water heaters, Solar Energy 173 (2002) 287-292.

[7] S. Ito, N. Miura, K. Wang, Performance of heat pump using direct expansion solar collectors, Solar Energy 65 (1999) 189-196.

[8] M.N.A. Hawlader, S.K. Chou, M.Z. Ullah, The performance of a solar assisted heat pump water heating system, Applied Thermal Engineering 21 (2001) 1049-1065.

[9] G.L. Morrison, T.M. Anderson, Behnia, Seasonal performance rating of heat pump water heaters, Solar Energy 76 (2004) 147-152. 